\title{
Keeping up with the Joneses - the Effect of Individual Cultural Values on Conspicuous Consumption Aslıhan Kıymalıoğlu ${ }^{1}$ Eyyüp Yaraş ${ }^{2}$ \\ Duygu Aydın Ünal ${ }^{3}$
}

\begin{abstract}
This paper aims to investigate the relationship between individual cultural values and brand consciousness, and the effect of this relationship on conspicuous consumption. Individual cultural values scale developed by Yoo et al. (2011), based on five dimensions of national culture propounded by Hofstede, were used to develop hypotheses pertaining to their effects on brand consciousness and the effect of brand consciousness on conspicuous consumption. Results of the study provide support for some of the hypothesised effects which suggest that indeed, certain dimensions of culture are key factors in determining whether or not consumers use brands as status symbols and for showing off. The finding that conspicuous consumption is used as a tool for expressing our power distance and masculinity values reveals the symbolic value of consumption. These results offer possibilities for using cultural values on an individual level and analysing their effect on consumption attitudes of consumers.
\end{abstract}

\section{Keywords}

Conspicuous consumption • Individual national cultures $\bullet$ Brand consciousness

Theories on consumption culture has changed in time from the proposition of Levitt (1984), who suggested that the world is "homogenous" in terms of consumption patterns leading to the global success of uniform products and that companies employing different marketing strategies for different cultures may fail. Douglas and Wind (1987) challenged his approach, suggesting that a globally standardized product cannot be successful due to cultural, economic, administrative and geographical differences between and within countries. Employing Hosftede's cultural distance approach across countries, much research has been conducted on the international marketing strategies of firms who intend to expand their operations (Azar \& Drogendijk, 2016; Samaha, et al., 2014; Blocker \& Flint, 2007). Therefore, it is crucial to fully understand the effect of culture on consumption behaviour as consumers may vary in their behaviour in different cultural contexts (Shaw \& Clarke, 1998).

1 Aslıhan Kıymalıoğlu (Dr. Lecturer), Akdeniz University, Faculty of Business Administration, Department of Economics and Finance, Antalya, Turkey. Email: aslihank@akdeniz.edu.tr

2 Eyyüp Yaraş (Dr.Lectuer), Akdeniz University, Faculty of Economics and Administrative Sciences, Department of Business, Antalya, Turkey. Email: eyaras@akdeniz.edu.tr

3 Corresponding author:Duygu Aydın Ünal (Dr. Lecturer), Akdeniz University, Maritime Faculty, Department of Maritime Business Management, Antalya, Turkey. Email: duyguaydin@akdeniz.edu.tr 
Yet, recent research on consumer cultures suggested that considering all consumers in a country as having similar consumption attitudes may neglect major aspects in their spending patterns (Yoo, et al., 2011). It is assumed that consumers in a country, with an ascribed cultural classification, may display different consumption behaviour. Due to the heterogeneous structure of countries, imputing similar cultural characteristics for all members of that nation is considered as an oversimplification of the subject. When the communication channels and mobility opportunities are reckoned, ascribing the same culture scores to all members of a society will be less meaningful. Therefore, individual cultural values were developed by Yoo, Donthu and Lenartowicz (2011) in order to determine the effects of cultural aspects on individual consumption patterns.

Brand consciousness is another major characteristic of consumer decision-making affecting consumption attitudes of consumers and is defined as the mental orientation to choose well-known and highly advertised brand-name products (Sproles $\&$ Kendall, 1986). The underlying idea is that brands reflect one's personality (Nan $\&$ Heo, 2007). A high level of brand consciousness is an indicator of consumer acknowledgment of brands as status symbols and prestige. Brand conscious consumers depict their consciousness of self and personality traits and reduce purchase risks through brands (Liao \& Wang, 2009). Due to this perception, brand conscious consumers prefer expensive, well-known products rather than brands that are known less (Lehmann \& Winer, 1997). Regarding brands as an expression of self, they play a significant role in consumption patterns of individuals where they are evaluated according to their symbolic values rather than functional worth.

Considering the change in consumption patterns as consumers display a heterogeneous structure both globally and within national boundaries thanks to their difference in socio-demographic, economic and cultural characteristics; the objective of this research is to address the effect of individual cultural values on conspicuous consumption through brand consciousness. It is assumed that cultural differences create an important barrier for internationalization of products as this difference determines symbolic meanings and values ascribed to products and their brands (Shaw \& Clarke, 1998). Therefore, the role of brand consciousness is considered in the model as a factor affecting conspicuous consumption.

The model proposed in the study was realised by employing five individual cultural dimensions as independent variables affecting conspicuous consumption of consumers through brand consciousness. Using the CVSCALE developed by (Yoo, et al., 2011) to measure the cultural values of individuals and the brand consciousness scale developed by (Sproles \& Kendall, 1986), the model was tested through structural equation modelling where conspicuous consumption acted as the dependant variable. The next part of the article incorporates a literature review of the said variables, followed by an explanation of 
the research methodology and discussion on the results obtained.

\section{Theoretical Background and Hypothesis}

\section{Culture, Individual Culture and Brand}

\section{Consciousness}

Culture is defined as "the fundamental values, attitudes, beliefs, and patterns of thinking which are rooted in the view of a region or society of how the world works and how individuals and/or groups can and should operate in that world" (Brake, et al., 1995). This deep and widely discussed issue provides a sense of a common identity for individuals and plays a major role in shaping how people behave, act and respond to things in their communities.

The popular and extensive typology developed by Hofstede (1980) covered cultural differences among nations. Using data from a large multinational corporation, the author measured cultural dimensions in 64 countries and grouped them under 5 dimensions: power distance, individualism vs collectivism, masculinity vs femininity, uncertainty avoidance and long-term vs short-term orientation. The power distance index concerns the distribution of power within a society and the handling of inequalities by the populace. High power distance values indicate an acknowledgment that power is distributed unequally. The individualism dimension covers the perspective of individuals either with respect to taking care of themselves and their immediate families or preferring a tight framework where individuals expect their relatives and other members of society to take care of each other. This dimension is expressed in the "I" or "we" approach of individuals. The masculinity dimension concerns favouring achievement, heroism, assertiveness, competitiveness and material rewards. In contrast, femininity favours cooperation, modesty, caring for the weak, and quality of life. The fourth dimension, the uncertainty avoidance index, measures the degree of uncertainty and ambiguity felt by members of a society. The uncertainty of the future is especially emphasized and determines the attitudes of society towards this dimension: should the future be controlled or should it be left to simply happen? Countries with a high uncertainty avoidance have rigid codes of behaviour, whereas countries with lower index values have a more relaxed attitude. The long-term versus short-term orientation considers the emphasis on the past or the future. Cultures with long-term orientation motivate individuals to invest for the future and adapt traditional values to the future. Short-term oriented cultures on the other hand, motivate individuals to spend and earn quickly. Traditions are important for and valued by these cultures.

Through providing shared values, ideas and other symbols for a society, culture affects individual-level consumption structure, decision-making processes, purchasing patterns and communication about the product (Singh, 2006). However, it is becoming less meaningful to assign similar cultural values to all members of a so- 
ciety when their heterogeneous and mobile structure is considered (Yoo, et al., 2011). Hofstede developed national culture typology to distinguish countries from each other, however the approach incorporates shortcomings as it cannot explain individual behaviour (Straub, et al., 2002) and he also remarks that the country-level dimensions cannot be used to predict and explain individual behaviour (Hofstede, 2011).

Culture is defined at a national level, yet it is necessary to measure individual-level culture and to analyse whether individuals display a similar tendency within the boundaries of a nation. This fact is more notable in countries with a heterogeneous population. Therefore, only considering national culture and using these values to target individual customers may not work. The Individual Cultural Values Scale (CVSCALE) was developed by Yoo et al. (2011) as a psychometrically sound measure of individual cultural value dimensions. It is acknowledged that consumer cultural characteristics affect consumers' view of themselves (Wong \& Ahuvia, 1998) and conspicuous consumption is the most evident form of this perspective as luxury goods are the most visible forms. Analysing individual cultural values would provide more sensitive results than treating all members of a nation the same. Manrai et al. (2001) found that cultural values of individuals are changing due to exposure to western brands and advertising, and collectivist values are being replaced by individualistic values. Considering the effect of culture on consumption patterns -espe- cially on conspicuous consumption - it is considered necessary to analyse individual level cultural values to understand how buying behaviour is shaped.

Individuals with different cultural values display varying attitudes in their consumption behaviours. Literature provides some studies analysing the difference between consumers in terms of their cultural values (Aaker \& Schmitt, 1998; Chang \& Nelson, 2016; Yim, et al., 2014; Liao \& Wang, 2009; Manrai, et al., 2001). Both of these studies use only the individualism dimension of cultural values, which suggests that consumers use brands as an indicator of their individualism and use brands to separate themselves from other people. Yet, it is considered necessary to test the role of other cultural value dimensions in shaping brand consciousness and conspicuous consumption of consumers. It can be assumed that individuals with high power distance values can have high brand consciousness as they consider brands as a tool to reinforce the inequality and their superior position in society (Zinkhan \& Prenshaw, 1994; Bardakçı \& Akınc1, 2014). Brands act as status symbols which are highly desired. With the individualism dimension of consumer culture, it has been established in relevant studies that cultures with high collectivism values prefer buying status enhancing brands as it is important what known others think about the individual in these cultures. Therefore, their brand consciousness levels are high. In terms of masculinity values, consumers are considered to equate brands with manly attributes such as heroism, competitiveness, material 
rewards and use them to support their will to achieve. On the other hand, consumers with high uncertainty avoidance values will benefit from brands to reduce their risk perception and to strengthen their status. Therefore, their brand consciousness levels will be high. With regards to long term orientation, which deals with emphasis on the past or the future, brand consciousness is dominant for individuals with short-term orientation as consumers with long-term orientation tend to be more price-conscious and conspicuous consumption is a taboo for them. Yet, individuals with short-term orientation will be more likely to spend on well-known brands and will be more inclined to utilise consumption as a way of showing off.

Brand consciousness refers to the orientations of consumers' towards purchasing well-known, more expensive products over other brands (Sproles \& Kendall, 1986). Its notion that "brands play an important role in the psychological process that precedes the buying act" also reflects the consumption attitudes (Nelson \& McLeod, 2005). Consumers with high brand consciousness tend to buy well-known and luxury products to display their wealth or status; to "portray their fashion consciousness, express personality traits and reduce risk in purchase decisions" (Liao \& Wang, 2009). Brands serve as a tool in reflecting the identity of the owner. Expensive, high-quality products act as an expression of the image that the owner wants to display to significant others. Therefore, consumers, who have high brand consciousness, are highly sensitive to the user image conveyed by the brand (Nan \& Heo, 2007). Grounding on these assumptions, the hypotheses of the study regarding cultural values and their relationships with brand consciousness were established as follows:

The greater the power distance $\left(H_{p}\right)$, collectivism $\left(H_{2}\right)$, uncertainty avoidance $\left(H_{3}\right)$, masculinity $\left(H_{4}\right)$ and short-term orientation $\left(H_{5}\right)$ value of consumers', the greater their brand consciousness will be.

Brand consciousness influences consumer behaviour and differs in individual-levels (Lachance, et al., 2003). The role played by brands and consumers' consciousness is more prominent when conspicuous consumption behaviour of consumers, i.e. signalling status through acquiring and displaying visible goods, is considered. This relationship has been verified in studies where the effect of brand consciousness on conspicuous consumption was measured (Yim, et al., 2014; Giovannini, et al., 2015; Mann \& Sahni, 2014). The findings of the studies presented the fact that individuals with high brand consciousness also have high levels of conspicuous consumption.

\section{Conspicuous Consumption}

Emerging as a criticism against the neoclassical theory of consumption, which is based on utility maximization of individuals, conspicuous consumption, defined as "a deliberate engagement in symbolic and visible purchase, possession and usage of products and services imbued with scarce economic and cultural capital with the motivation to communicate a distinctive 
self-image to others" (Chaudhuri, et al., 2011), develops a framework where preferences of individuals are determined according to their positions in social hierarchy (Veblen, 1899). Grounding on 'we are what we have' perception, conspicuous consumption is considered by Veblen (1899) as the most significant factor shaping consumer behaviour not only for wealthy, but for all social classes where people spend money on consumption goods to indicate their wealth to other members of said society. The main argument of Veblen's theory is the demonstration of wealth toward others, which causes a positive correlation between wealth and conspicuous consumption (Braun \& Wicklund, 1989). The theory proposes that individuals long for status and display it through material display of wealth. People consume goods in order to display their status and success to other people who are significant for them. In many cases, consumer decisions on purchasing a good does not arise from the intrinsic utility of consuming that good; instead, its symbolic meaning is the motivation for buying it (Corneo \& Jeanne, 1997).

Consumer purchase behaviour in neoclassical theory suggests that there is a negative relationship between the price of a good and consumers' demand for that product, and when all else is equal, an increase in price would result in a decrease in demand. Here, individuals are considered as "economic man" and the sales potential of a product is determined by the price of said product and the resources of the individual. However, the theory proposed by Veblen suggests an opposite approach, where the product becomes more attractive when its price is high which is considered as an indicator of status and prestige. Thus, the demand for a product increases only because of its higher price.

These benefits play an important role in purchasing preferences of products which may appear to be purchased for their utility but in fact serve as a means of wealth and status indicator. Satisfaction from consuming the product arises not from its functional benefits but from the reaction of significant others to whom the individual can display his wealth and purchasing power. Consumption of highly conspicuous goods is used as a tool to advertise one's affluence and thus, achieving greater social status (Corneo \& Jeanne, 1997). This never ending search for status causes paying a higher price for a functionally equivalent good (Han, et al., 2010). Thus, the utility derived from a product is defined over consumption and status instead of consumption and price (Bagwell \& Bernheim, 1996). In this way, purchases that were once considered extravagant have gained an important social function and buying the goods became the ultimate goal instead of practical values associated with their usage (Chaudhuri \& Majumdar, 2006).

The concept of the "Veblen effect" arises when consumers are willing to pay more for a product than a functionally equivalent item. In other words, willingness to pay more for a product increases in parallel with its price. The derived benefit is defined through consumption and status and 
thus, conspicuous consumption announces and enables wealth. Veblen (1899) proposed that individuals fall into two groups in terms of their motivations for consuming conspicuous goods: invidious comparison and pecuniary emulation. Invidious comparison refers to consumption patterns by the wealthy classes to distinguish themselves from the lower classes, whereas pecuniary emulation occurs as a result of conspicuous consumption by lower classes wishing to be perceived as members of a higher class. Both of these approaches arise as production has lost its privileged status and consumption became the means by which individuals defined themselves and how they would like to be perceived by others (Chaudhuri \& Majumdar, 2006; Bagwell \& Bernheim, 1996).

Bakewell and Mitchell (2003) cite that each generation exceeds the previous one by becoming more conspicuous in consumption as they are more and more assimilated in a materialistic culture. Still, the meanings ascribed to consumption display some differences between cultures. That is, consumption decisions are linked to their cultural contexts (Shaw \& Clarke, 1998). Therefore, this study is grounded on the cultural values in individual levels and their effect on conspicuous consumption through brand consciousness.

On the grounds of the literature findings on the relationship between brand consciousness and conspicuous consumption, the last hypothesis of the research was developed as follows and the hypothesised relationships were displayed in figure 1:
$H_{6}:$ The greater the brand consciousness of consumers', the higher their conspicuous consumption will be.

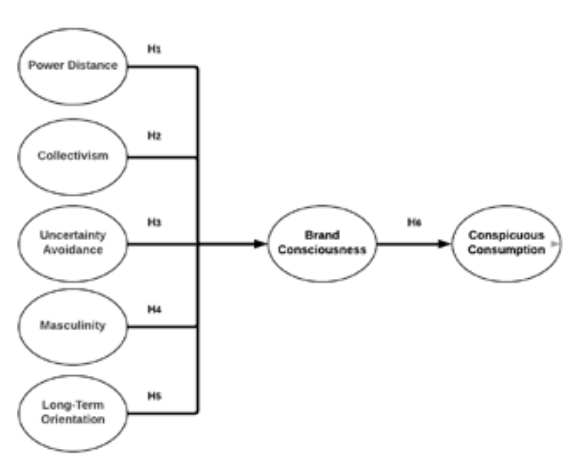

\section{Methodology}

\section{Measurement Instruments and Sample}

The study utilized survey data obtained through a questionnaire with four parts. The first part measured individual cultural values of consumers through the CVSCALE developed by Yoo, Donthu, \& Lenartowicz (2011). The scale consists of five parts, each dedicated to measuring one of Hofstede's cultural value dimensions, with a total of 26 items, each measured on five-point Likert Scales anchored by $1=$ strongly disagree and $5=$ strongly agree. Brand consciousness of consumers was tested by using the scale developed by Sproles \& Kendall (1986) with 6 questions, again measured on five-point Likert Scales ( $1=$ strongly disagree, $5=$ strongly agree). The third part had survey questions on conspicuous consumption, which was measured by the scale of Chaudhuri, Mazumdar, \& Ghoshal (2011). Consumer demographics that were used to monitor 
sample characteristics constituted the last part of the questionnaire. A bilingual person has translated the questionnaire items into Turkish and the items were, then, back translated into English to check and minimize any idiomatic or colloquialistic wording (Neteyemer, et al., 1991)

A total of 921 surveys were distributed through Google forms which were delivered on social media (Facebook) and face to face interviews by using the convenience sampling method and 466 usable results were retained. Demographics of the sample indicated that half of the participants had a high school degree or less (56\%); and more than half of the respondents stated that they could satisfy their vital and other needs $(55.4 \%)$ whereas $17.6 \%$ stated they could only meet their vital needs and the rest indicated that they had enough income to make savings. $70 \%$ of the sample were single and gender was equally distributed. More than half of the participants were aged between 21 and 30 (57.7\%) while $23.2 \%$ were aged between 31 and 40 .

Before proceeding to hypothesis testing, the scales in the survey were tested for their reliability and validity. The findings indicated that reliability values were satisfactory for the sample for all of the individual cultural value dimensions where alpha values were .708 for power distance, .801 for uncertainty avoidance, .862 for collectivism, .709 for long-term orientation and .762 for masculinity. Reliability analysis provided results that were similar to the original scale development research by Yoo et al. (2011) which could be consid- ered as a contribution to the cross-national generalizability of the scale. The Conspicuous consumption scale, developed by Chaudhuri et al. (2011), scored .930 and brand consciousness scale (Sproles \& Kendall, 1986) scored .887 in their Cronbach's alpha values.

Explanatory factor analysis results also provided satisfactory findings. Items with loadings less than .70 were eliminated on the grounds of the administrative decision rule specified by Fornell and Larcker (1981) where items loading less than .707 can be regarded as unreliable and eliminable (Shimp \& Sharma, 1987). The final factor structure of the scale consisted of 16 scale items explaining $69.5 \%$ of the variance where all items were loaded on the respective factors as suggested in the theoretical model of Yoo et al. (2011). Both the conspicuous consumption scale and brand consciousness scale yielded satisfactory findings of factor analysis, explaining $70 \%$ and $81 \%$ of the total variance, respectively, with factor scores above .70 .

\section{Empirical Results}

Structural Equation Modelling was used to test the hypothesized model among the variables where individual cultural value dimensions affect brand consciousness and brand consciousness affects conspicuous consumption, and the model was tested using AMOS 18.

Data from 466 surveys was used in conducting the analysis which was estimated with the maximum likelihood method. 
The model was found to have acceptable fit $\left(\chi^{2}=434.286, \mathrm{GFI}=.933\right.$, AGFI $=.914$, $\mathrm{RMR}=.050$, RMSEA $=.039)$ and the $\mathrm{R}^{2}$ values of brand consciousness and conspicuous consumption were found to be .27 and .77 , respectively (see Table 1). These findings indicate that whereas brand consciousness is an important determinant of conspicuous consumption, the same inference could not be made for brand consciousness, as other variables need to be included in the model to explain the variance in brand consciousness.

Table 1. Maximum likelihood estimations for structural regression model

\begin{tabular}{lc}
\hline Parameter & Estimate \\
\hline Power Distance & $.466^{* *}$ \\
Individualism & -.181 \\
Uncertainty Avoidance & -.165 \\
Long-Term Orientation & -.050 \\
Masculinity & $.220^{* *}$ \\
Brand Consciousness & $.771^{* *}$ \\
\hline $\mathbf{R}^{2}$ & \\
\hline Brand Consciousness & $.27^{* *}$ \\
Conspicuous Consumption & $.77^{* *}$ \\
\hline Goodness of fit indices & \\
\hline$\chi^{2}$ & 434.286 \\
$d f$ & 255 \\
$p$ value & .000 \\
GFI & .933 \\
AGFI & .914 \\
RMR & .050 \\
RMSEA & .039 \\
\hline$* *$.
\end{tabular}

**denotes a statistically significant relationship $(p<.001)$

$\mathrm{H}_{1}-\mathrm{H}_{5}$ predict the relationship between individual cultural value dimensions and brand consciousness. The results of the analysis for these hypotheses indicate that the parameters were significant only for Power Distance and Masculinity Values, supporting $\mathrm{H}_{1}$ and $\mathrm{H}_{5}$. The findings indicate that individuals who have high power distance values are more brand conscious, supporting the assumption that consumers use brands as tools for reinforcing their power within society and as an indicator that intensifies the social hierarchy among individuals. Also, the significance of the masculinity dimension supports the perception that individuals consider brands as synonymous with man power. They benefit from brands to display and support their strength. The other cultural value dimensions were found insignificant, not supporting the relevant hypothesis. Although it was expected to find the significant effect of collectivism, short-term orientation and uncertainty avoidance on brand consciousness, current results indicated no significant relationship. The results could be ascribed to the sample characteristics and to the national culture of the individuals participating in the study. For example, the cultural value dimension of Turkey for long-term orientation did not display any dominant cultural preference in Hofstede's study. Therefore, that dimension did not result in significant values in current research.

In testing $\mathrm{H}_{6}$, a positive relationship was found between brand consciousness and conspicuous consumption. This finding is similar to the results of previous studies, which support the idea that consumers use brands as a reflection of their identity and thus, their consciousness of brands increase in parallel with their conspicuous consumption attitudes.

\section{Conclusion and Limitations}

An important motivator of consumer behaviour - prestige-seeking - has been subject to numerous studies (Vigenron \& Johnson, 1999; Eastman, et al., 1999; 
Goldsmith \& Clark, 2012). "Keeping up with the Joneses" shapes the consumption patterns of consumers where "wasteful and lavish consumption expenses [are used] to enhance social prestige" (Chaudhuri \& Majumdar, 2006). Various psychological and brand related factors shape this attitude of consumers (Shukla, 2008). Among these factors, cultural values play a significant role as culture is an important determinant of consumption behaviour (McCracken, 1986). Yet, there is a limited number of studies discussing the effect of culture on consumption patterns individually as people living in the same country do not necessarily share same cultural values.

Therefore, this research aims to fill this gap by measuring individual cultural values of consumers, and its effect on conspicuous consumption through brand consciousness. Previous studies have generally employed only one of the cultural values dimensions. This study differs from them in terms of testing five cultural value dimensions individually, which has been used by (Yoo, et al., 2011) while developing the CVSCALE. The results indicate the positive and significant effect of power distance and masculinity on brand consciousness, and brand consciousness on conspicuous consumption. However, the other three dimensions were not found significant, which could be the result of sample characteristics and also the national cultural values of the sample, as previously mentioned.

Previous studies used individual cultural dimensions within different contexts. Baker et al. (2013) used three of Hofstede's dimensions as moderators in the relationship between emotions and complaint behaviour. Soares (2005) studied the effect of individual cultural dimensions on exploratory and risk taking behavior, supporting the CVSCALE. The study of Richter, et al. (2016) used the scale to develop cultural archetypes in 10 countries.

Testing the scale developed by (Yoo, et al., 2011) in a different cultural context is another contribution of this research. The authors have already validated the scale through testing it on different samples, both demographically and nationally. However, as it is a relatively new scale, there are no valid translations and reliability analysis for most of the countries. The current research contributes to this generalizability by using the scale in a different country. Results also strengthen an important issue stated in literature as the current cross-cultural business papers on culture assessment methods do not present a framework due to the lack of universally accepted scales (Prasongsukarn, 2009). Current study supports the usefulness of the CVSCALE.

Yoo, et al. (2011) have verified the adequacy of the CVSCALE for global markets. Segmentation of consumers on an individual cultural basis would enable practitioners to find similar consumer segments across different countries which would in turn allow development of similar marketing programs. This segmentation and data obtained from it would be useful for companies that would like to operate in new markets. Instead of limiting themselves to specific countries with similar 
cultural tendencies, companies can penetrate worldwide markets. Improvements in technology and e-commerce will enable the implementation of such a strategy and access to these segments in each country

The findings of the research will provide novel questions to be addressed in further studies, such as analysing the reflection of individual cultural values on specific purchase patterns of consumers. This effect will be compared for different product types and is expected to reveal sound insights into varying cultural value dimensions. Furthermore, a comparison of more polarised segments in the cultural values will be made to detail the effect of individual cultural values on consumer behaviour. This empirical research is nevertheless subject to certain limitations. The demographic profile of the participants, who were selected from Turkish individuals, and sampling methods employed hinders obtaining more precise results for cultural value dimensions and for the generalizability of the results.

\section{References}

Aaker, J. L. \& Schmitt, B. H., (1998). The Influence of Culture on the Self-Expressive Use of Brands. \%1 içindeAdvances in Consumer Research. Provo, Utah: Association for Consumer Research, p. 12.

Azar, G. \& Drogendijk, R., (2016). Cultural distance, innovation and export performance: An examination of perceived and objective cultural distance. European Business Review, 28(2), pp. 176-207.

Bagwell, L. \& Bernheim, B. D., (1996). Veblen effects in a theory of conspicuous consumption. The American Economic Review, 86(3), pp. 349-373.

Bagwell, L. S. \& Bernheim, D. B., (1996). Veblen effects in a theory of conspicuous consumption. American Economic Review, 86(3), pp. 349-373.

Baker, T. L., Meyer, T. \& Chebat, J.-C., (2013). Cultural impacts on felt and expressed emotions and third party complaint relationships. Journal of Business Research, 66, pp. 816-822.

Bakewell, C. \& Mitchell, V.-W., (2003). Generation y female consumer decision-making styles. International Journal of Retail and Distribution Management, 31(2), pp. 95-106.

Bardakçı, A. \& Akıncı, M. (2014). Türkiye'de ürün markalamada yabanci dil kullanimi: sebepler ve sonuçlar. Tüketici ve Tüketim Araştırmalarl Dergisi, 6(1), pp. 1-26.

Blocker, C. P. \& Flint, D. J. (2007). Exploring the dynamics of customer value in cross-cultural business relationships. Journal of Business and Industrial Marketing, 22(4), pp. 249-259.

Brake, T., Walker, D. M. \& Walker, T. (1995). Doing Business Internationally: The Guide to Cross-Cultural Success. New York: Irwin Publishing.

Braun, O. L. \& Wicklund, R. A. (1989). Psychological antecedents of conspicuous consumption. Journal of Economic Pscyhology, 10(2), pp. 161-187.

Chang, J. \& Nelson, M. R. (2016). The effects of vertical individualism on status consumer orientations and behaviors. Psychology and Marketing, 33(5), pp. 318-330. 
Chaudhuri, H. R. \& Majumdar, S. (2006). Of diamonds and desires: understanding conspicuous consumption from a contemporary marketing perspective. Academy of Marketing Science Review, 11, pp. 1-18.

Chaudhuri, H. R., Mazumdar, S. \& Ghoshal, A. (2011). Conspicuous consumption orientation: conceptualisation, scale development and validation. Journal of Consumer Behaivour, 10, pp. 216-224.

Corneo, G. \& Jeanne, O. (1997). Conspicious consumption, snobbism and conformism. Journal of Public Economics, 66, pp. 55-71.

Douglas, S. P. \& Wind, Y. (1987). The Myth of Globalization. Columbia Journal of World Business, Winter.pp. 19-29.

Eastman, J. K., GoldSmith, R. E. \& Flynn, L. R. (1999). Status consumption in consumer behavior: Scale development and validation. Journal of Marketing Theory and Practice, 7(3), pp. 41-52.

Giovannini, S., Xu, Y. \& Thomas, J. (2015). Luxury consumption and generation y consumers: Self, brand consciousness and consumption motivations. Journal of Fashion Marketing and Management, 19(1), pp. 22-40.

Goldsmith, R. E. \& Clark, R. A. (2012). Materialism, status consumption, and consumer independence. Journal of Social Psychology, 152(1), pp. 43-60

Han, y. J., Nunes, J. C. \& Xavier, D., (2010). Signaling status with luxury goods: The role of brand prominence. Journal of Marketing, 74, pp. 15-30.

Hofstede, G. (1980). Culture's consequences: International differences in work-related values. Beverly Hills: Sage Publications.

Hofstede, G. (2011). Dimensionalizing cultures: The hofstede model in context. Online Readings in Psychology and Culture, 2(1), pp. 2-25.

Lachance, M. J., Beaudoin, P. \& Robitaille, J. (2003). Adolescents' brand sensitivity in apparel: Influence of three socialization agents. International Journal of Consumer Studies, 27(1), pp. 47-57.
Lehmann, D. R. \& Winer, R. S. (1997). Product Management. Sydney: Irwin.

Levitt, T. (1984). The Globalization of Markets McKİnsey Quarterly, Summer.pp. 2-20.

Liao, J. \& Wang, L (2009). Face as a mediator of the relationship between material value and brand consciousness. Psychology and Marketing, 26(11), pp. 987-1001.

Mann, B. J. S. \& Sahni, S. K. (2014). Exploring the drivers of status consumption for the wedding occasion. International Journal of Market Research, 57(2), pp. 179-202.

Manrai, L. A., Lascu, D.-L., Manrai, A. K. \& Babb, H. W. (2001). A cross $\square$ cultural comparison of style in eastern european emerging markets. International Marketing Review, 18(3), pp. 270-285.

McCracken, G. (1986). Culture and consumption: A theoretical account of the structure and movement of the cultural meaning of consumer goods. Journal of Consumer Research, 13, pp. 71-84.

Nan, X. \& Heo, K (2007). Consumer responses to corporate social responsibility (CSR) initiatives: examining the role of brand-cause fit in cause-related marketing. Journal of Advertising, 362, pp. 63-74.

Nelson, M. R. \& McLeod, L. E. (2005). Adolescent brand consciousness and product placements: Awareness, liking and perceived effects on self and others. International Journal of Consumer Studies, 29(6), pp. 515-528.

Neteyemer, R., Durvasula, S. \& Lichtenstein, D. R. (1991). A cross-national assessment of the reliability and validty of the CETSCALE. Journal of Marketing Research, 28(3), pp. 320-327.

Prasongsukarn, K. (2009). Validating the cultural value scale (CVSCALE): A Case Study of Thailand. ABAC Journal, 29(2), pp. 1-13.

Richter, N. F. et al., 2016. Using cultural archetypes in cross-cultural management studies. Journal of International Management, 22, pp. 63-83.

Samaha, S. A., Beck, J. T. \& Palmatier, R. W (2014). The role of culture in international relationship marketing. Journal of Marketing, 78(5), pp. 78-98 
Shaw, D. S. \& Clarke, I. (1998). Culture, consumption and choice: Towards a conceptual relationship. Journal of Consumer Studies and Home Economics, 22(3), pp. 163-168.

Shimp, T. A. \& Sharma, S. (1987). Consumer ethnocentricism: Construction and validation of the CETSCALE. Journal of Marketing Research, 24(3), pp. 280-289.

Shukla, P. (2008). Conspicuous consumption among middle age consumers: Psyhcological and brand antecedents. Journal of Product and Brand Management, 17(1), pp. 25-36.

Singh, S., 2006. Cultural differences in, and influences on, consumers' propensity to adopt innovations. International Marketing Review, 23(2), pp. 173-191.

Soares, A. M. (2005). The Influence of Culture on Consumers: Exploratory and Risk Taking Behavior. Unpublished Doctoral Dissertation: Escola de Economia a Gestao: University of Minho.

Sproles, G. B. \& Kendall, E. L. (1986). A methodology for profiling consumers' decision-making styles. Journal of Consumer Affairs, 20(2), pp. 267-279.

Straub, D. et al. (2002). Toward a theory-based management of culture. Journal of Global Information Management, 10(1), pp. 13-23.
Veblen, T. (1899). The Theory of the Leisure Class. s.1.:Oxford University Press.

Vigenron, F. \& Johnson, L. W. (1999). A review and a conceptual framework of prestige-seeking consumer behavior. Academy of Marketing Science Review, 1, pp. 1-15.

Walsh, G. et al. (2016). Developing and validating a scale of consumer brand embarrassment tendencies. Journal of Business Research, 69(3), pp. 1138-1147.

Wong, N. Y. \& Ahuvia, A. C. (1998). Personal taste and family face: Luxury consumption in confucian and western societies. Psyhcology and Marketing, 15(5), pp. 423-441.

Yim, M. Y.-C. et al (2014). Drivers of attitudes towards luxury brands. International Marketing Review, 31(4), pp. 363-389.

Yoo, B., Donthu, N. \& Lenartowicz, T. (2011). Measuring hofstede's five dimensions of cultural values and the individual level: Development and validation of CVSCALE. Journal of International Consumer Marketing, 23(3-4), pp. 193-210.

Zinkhan, G. M. \& Prenshaw, P. J. (1994). Good life images and brand name associations: Evidence from Asia, America, and Europe. Advances in Consumer Research, 2, pp. 496-500. 